\title{
INOVASI PEMBELAJARAN PROYEK BERBASIS BUDAYA LOKAL UNTUK MENINGKATKAN KREATIVITAS PEMBELAJARAN TATA GRAHA
}

\author{
Ni Desak Made Sri Adnyawati \\ Jurusan Pendidikan Kesejahteraan Keluarga \\ FTK-Universitas Pendidikan Ganesha Singaraja - Bali \\ Email: adnyawati@ymail.com
}

\begin{abstract}
Abstrak. Penelitian tindakan kelas ini dilakukan di jurusan PKK, FTK Undiksha tahun 2013 yang bertujuan untuk mengetahui tentang (1) penerapan model pembelajaran proyek berbasis budaya lokal dalam pembelajaran tata graha, (2) peningkatan kreativitas mahasiswa dalam pembelajaran tata graha melalui pembelajaran proyek berbasis budaya lokal, dan (3) respon mahasiswa terhadap penerapan model pembelajaran proyek berbasis budaya lokal. Penelitian ini melibatkan 24 orang mahasiswa dengan teknik pengumpulan data melalui observasi dan angket. Observasi digunakan untuk mengamati kreativitas mahasiswa, dan angket digunakan untuk mengumpulkan data respon mahasiswa. Pengamatan kreativitas mahasiswa dilakukan pada proses perancangan desain rangkaian bunga lokal, desain rangkaian bunga dipadukan dengan janur, proses merangkai bunga dengan janur, dan hasil rangkaian bunga dengan janur. Analisis dilakukan secara deskriptif. Hasil penelitian menunjukkan bahwa penerapan model pembelajaran proyek berbasis budaya lokal dalam pembelajaran tata graha dilakukan melalui 5 langkah yaitu (a)penentuan tema rangkaian bunga lokal dipadukan dengan janur, (b)penetapan konteks belajar dengan pemanfaatan bunga lokal dipadukan dengan janur, (c)merencanakan aktivitas melalui persiapan, pemilihan, dan pemakaian bunga lokal dipadukan dengan janur, (d)memproses aktivitas penggunaan bunga lokal dipadukan dengan janur, dan (e)penerapan aktivitas penyelesaian proyek berupa rangkaian bunga lokal dipadukan dengan janur. Terdapat peningkatan kreativitas pembelajaran graha melalui pembelajaran proyek berbasis budaya lokal sebesar 4,6 yaitu dari skor rata-rata sebesar 83,7 menjadi 88.3. Artinya peningkatan tersebut dari kategori baik menjadi sangat baik. Respon mahasiswa terhadap penerapan model pembelajaran proyek berbasis budaya lokal terkategori sangat baik.
\end{abstract}

Kata Kunci : kreativitas, pembelajaran proyek berbasis budaya lokal, tata graha.

\begin{abstract}
The classroom action research was conducted in the department of the PKK, FTK Undiksha in 2013 which aims to find out about (1) the implementation of project based learning model in the local culture of learning maid, (2)improvement of student creativity in learning maid through project based learning local culture, and (3)the student's response to the implementation of project based learning model of the local culture. The study involved 24 students with the techniques of collecting data through observation and questionnaire. Observations are used to observe the students' creativity, and questionnaires were used to collect student response data. Observations made on students' creative design process local floral design, floral design combined with leaf, flower arranging process with leaf, flower arrangements and the results of the leaf. The analysis was performed descriptively. The results showed that the implementation of project based learning model in the local culture of learning housekeeping is done through 5 steps: (a) determination of local floral theme combined with coconut, (b) the determination of the context of learning with the use of local interest combined with a coconut, (c) plan activities through the preparation, selection, and use of local interest combined with a coconut, (d) processing activity combined with the use of local flower leaf, and (e) completion of project implementation activities such as local flower arrangements combined with coconut. There is an increase in creativity housekeeping learning through project based learning local culture by 4.6, from an average score of 83.7 into 88.3. This means that the increase of both categories being very good. Student response to the application of project based learning model categorized the local culture very well.
\end{abstract}

Keywords : project learning based local culture, creativity, housekeeping. 


\section{PENDAHULUAN}

Mata kuliah Tata Graha merupakan salah satu mata kuliah produktif kejuruan di jurusan PKK sesuai kurikulum 2013. Mata kuliah ini bertujuan agar mahasiswa dapat membuat rangkaian bunga yang dikombinasikan dengan janur yang kreatif dan inovatif sesuai fungsi serta mampu menumbuhkan entrepreneurship melalui pembelajaran proyek berbasis budaya lokal. Mahasiswa dapat memanfaatkan bahan utama maupun bahan tambahan yang bersifat lokal. Artinya penerapan budaya lokal dalam pembelajaran tata graha secara konteks melalui penggunaan bahan, yaitu bahan-bahan yang terdapat di lingkungan terdekat pembelajaran. Bahan utama yang identik dengan budaya local Bali antara lain bunga kamboja, medori, jempiring, dan janur dengan berbagai irisan unik. Kreativitas mahasiswa yang bersifat inovatif sebagai perwujudan ide, gagasan dalam bentuk karya nyata berupa produk-produk yang variatif original.

Orientasi produk karya inovatif mahasiswa adalah untuk menumbuhkan jiwa kewirausahaannya, karena sesuatu yang original memberikan peluang tinggi untuk pengembangan kewirausahaan atau entrepreneurship. Hal ini sesuai dengan pendapat Zimmerer (1996) bahwa kewirausahaan atau entrepreneur merupakan suatu proses penerapan kreativitas dan inovasi dalam memecahkan persoalan dan menemukan peluang untuk memperbaiki kehidupan. Artinya dengan berkreasi terhadap rangkaian bunga yang dikombinasikan dengan janur menghasilkan sesuatu yang baru diharapkan mampu memberikan nilai tinggi untuk mendapatkan peluang dipasaran.

Proses pembelajaran tata graha ini menekankan pada kebebasan mahasiswa untuk berapresiasi di bidang seni merangkai bunga dan janur dari proses perancangan, perwujudan karya nyata, dan evaluasi akhir suatu produk rancangan. Rangkaian bunga dan janur yang notabene saat ini difungsikan di setiap sisi ruangan, dalam kondisi apapun sehingga hal ini harus direspon melalui pengemasan pembelajaran tata graha. Oleh sebab itu kurikulum produktif ini memberikan tantangan dalam pembelajaran sehingga hasil dalam bentuk karya nyata bermanfaat bagi masyarakat sesuai dengan kondisi saat ini yaitu Bali dikenal sebagai daerah pariwisata. 
Kondisi saat ini di beberapa hotel dijumpai rangkaian bunga dikombinasikan dengan janur sebagai bahan dekorasi yang sekaligus memberikan nilai estetis dan daya tarik bagi konsumen/ tamu. Oleh karena itu pembelajaran yang sebelumnya belum menuangkan secara spesifik nuansa budaya Bali dalam produk rangkaiannya sehingga terkesan monoton. Hal ini ditunjukkan pula bahwa rata-rata kreativitas mahasiswa berada pada kategori baik yaitu 83,7. Solusi untuk meningkatkan kreativitas mahasiswa dalam pembelajaran graha yaitu melalui penerapan pembelajaran proyek berbasis budaya Bali yang sekaligus nantinya mampu untuk menumbuhkan jiwa kewirausahaan atau entrepreneurship mahasiswa.

Pembelajaran Proyek berbasis budaya local dipandang tepat sebagai satu model untuk pendidikan teknologi dalam merespon isu-isu peningkatan kualitas pendidikan teknologi dan perubahan-perubahan besar yang terjadi di dunia kerja. Pembelajaran proyek merupakan model pembelajaran yang berfokus pada konsepkonsep dan prinsip-prinsip utama (central) dari suatu disiplin, melibatkan mahasiswa dalam kegiatan pemecahan masalah dan tugas-tugas bermakna lainnya, memberi peluang mahasiswa bekerja secara otonom mengkonstruk belajar mereka sendiri, dan puncaknya menghasilkan produk karya mahasiswa bernilai, dan realistik (BIE, 1999). Terkait dengan mata kuliah tata graha sebagai kurikulum produktif maka karya nyata sebagai hasil dari pembelajaran ini adalah perwujudan kreativitas desain rangkaian bunga dan janur yang inovatif. Itulah sebenarnya inti proyek yang dikerjakan secara kolaboratif, inovatif untuk menjawab tantangan IPTEKS dalam Seni Merangkai Bunga.

Pembelajaran Proyek yang dikenal pula dengan istilah Project Learning merupakan pendekatan instruksional yang komprehensif untuk melibatkan peserta didik secara berkesinambungan, kooperatif, dan penyelidikan. Pembelajaran Proyek berfokus pada konsep dan prinsip inti sebuah disiplin, memfasilitasi pebelajar untuk berinvestigasi, pemecahan masalah, dan tugas-tugas bermakna lainnya, students' centered, dan menghasilkan produk nyata (Santyasa, 2007). Selanjutnya dinyatakan pula bahwa karakteristik Pembelajaran proyek meliputi 4 komponen yaitu adanya isi, kondisi, aktivitas, dan hasil. 
Pembelajaran proyek memiliki potensi yang amat besar untuk membuat pengalaman belajar yang lebih menarik dan bermakna bagi usia dewasa, atau pelatihan tradisional untuk membangun keterampilan kerja (Gaer, 1998). Dalam Pembelajaran proyek pebelajar menjadi terdorong lebih aktif dalam belajar, pengajar sebagai fasilitator, pengajar mengevaluasi produk hasil kinerja pebelajar meliputi outcome yang mampu ditampilkan dari hasil proyek yang dikerjakan. Pembelajaran ini menekankan lingkungan belajar siswa aktif, kerja kelompok (kolaboratif), dan teknik evaluasi otentik (authentic assessment).

Kreativitas adalah kemampuan seseorang untuk menghasilkan komposisi, produk atau gagasan apa saja yang pada dasarnya baru, dan sebelumnya tidak dikenal pembuatnya. Kreativitas dapat berbentuk produk seni, kesusastraan, produk ilmiah, atau mungkin bersifat prosedural atau metodelogis. Ketut Suarni (1996) mengemukakan bahwa "kreativitas adalah kemampuan untuk menciptakan. Ciptaan ini tidak perlu seluruh produknya harus baru, mungkin saja gabungannya, kombinasinya, sedangkan unsur-unsur sudah ada sebelumnya”. Kreativitas tidak selalu berupa ciptaan baru secara menyeluruh tetapi terdapat unsur kebaruan dari aspek-aspek dalam rangkaian. Adanya unsur kebaruan dalam suatu rangkaian bunga dan janur sebagai wujud inovasi mahasiswa dengan mengacu pada lingkungan nyata pembelajaran.

Berdasarkan uraian tersebut maka kajian terfokus pada permasalahan bagaimanakah inovasi pembelajaran proyek tata graha berbasis budaya lokal untuk meningkatkan kreativitas mahasiswa jurusan PKK-Tata Boga FTK Undiksha tahun 2013? Sejalan dengan itu maka tujuan penelitian ini adalah untuk meningkatkan kreativitas mahasiswa melalui pembelajaran proyek berbasis budaya lokal. Secara praktis kajian ini sangat bermanfaat bagi mahasiswa agar selalu termotivasi dalam mengikuti pembelajaran, mampu mengantarkan mahasiswa untuk aktif, kreatif sehingga mampu meningkatkan kreativitas dan menumbuhkan entrepreneurship mahasiswa secara optimal. Selanjutnya hasil penelitian ini dapat memberikan manfaat bagi perbaikan kualitas pembelajaran di jurusan PKK, FTK Undiksha. 


\section{METODE}

Subyek penelitian ini adalah mahasiswa jurusan PKK yang memprogramkan mata kuliah tata graha tahun akademik 2013/2014 sebanyak 24 orang. Obyek penelitian adalah model pembelajaran proyek berbasis budaya lokal dan kreativitas mahasiswa. Rancangan penelitian tindakan kelas (classroom action research) melalui pelaksanaan pembelajaran yang dapat digambarkan pada table 1 .

Tabel 1. Sintaks Pembelajaran Proyek Berbasis Budaya Lokal bidang Tata Graha

\begin{tabular}{|c|c|c|c|c|}
\hline No & Kegiatan Dosen & Komponen & Kegiatan Mahasiswa & Langkah \\
\hline 1. & $\begin{array}{l}\text { Menjelaskan tujuan } \\
\text { pembelajaran, konsep } \\
\text { rangkaian bunga yang } \\
\text { dipadukan dengan janur, } \\
\text { memberikan demonstrasi } \\
\text { tentang contoh racikan janur, } \\
\text { memberikan tema proyek } \\
\text { untuk masing-masing } \\
\text { kelompok dalam upaya } \\
\text { memotivasi siswa agar } \\
\text { terlibat pada aktivitas belajar } \\
\text { yang sebenarnya. }\end{array}$ & $\begin{array}{l}\text { ISI : } \\
\text { Orientasi } \\
\text { mahasiswa pada } \\
\text { masalah aktual } \\
\text { dan autentik }\end{array}$ & $\begin{array}{l}\text { Memanfaatkan handout } \\
\text { untuk memahami } \\
\text { rangkaian bunga dan janur } \\
\text { secara konsep yang } \\
\text { akhirnya digunakan dasar } \\
\text { untuk mengembangkan } \\
\text { tema dalam bentuk desain. } \\
\text { Mahasiswa berada dalam } \\
\text { kelompok yang } \\
\text { ditetapkan(@2 orang) }\end{array}$ & Penentuan tema \\
\hline 2. & $\begin{array}{l}\text { Penetapan konteks belajar } \\
\text { dengan pemanfaatan bunga } \\
\text { lokal dipadukan dengan janur }\end{array}$ & & $\begin{array}{l}\text { Demonstrasi pembuatan } \\
\text { racikan janur sederhana } \\
\text { dengan analisis } \\
\text { karakteristik bunga local }\end{array}$ & $\begin{array}{l}\text { Penetapan } \\
\text { konteks } \\
\text { pembelajaran }\end{array}$ \\
\hline 3. & $\begin{array}{l}\text { Membimbing mahasiswa } \\
\text { mendesain dan } \\
\text { mengorganisasikan rangkaian } \\
\text { bunga, rangkaian bunga yang } \\
\text { dipadukan dengan janur. }\end{array}$ & $\begin{array}{l}\text { KONDISI: } \\
\text { Pengorganisa } \\
\text { sian mahasiswa } \\
\text { dalam belajar }\end{array}$ & $\begin{array}{l}\text { Membuat } 2 \text { desain } \\
\text { rangkaian sesuai tema pada } \\
\text { masing-masing kelompok. } \\
\text { Pembuatan desain } \\
\text { rangkaian bunga, desain } \\
\text { rangkaian bunga yang } \\
\text { dikombinasikan dengan } \\
\text { janur. }\end{array}$ & $\begin{array}{l}\text { Perencanaan } \\
\text { aktivitas dalam } \\
\text { bahan, alat, } \\
\text { waktu, dan } \\
\text { tempat. }\end{array}$ \\
\hline 4. & $\begin{array}{l}\text { Memfasilitasi mahasiswa } \\
\text { untuk membuat rangkaian } \\
\text { sesuai tema dengan bahan- } \\
\text { bahan lokal. }\end{array}$ & $\begin{array}{l}\text { AKTIVITAS: } \\
\text { Fasilitasi/ } \\
\text { Bimbingan } \\
\text { praktikum } \\
\text { dalam kelompok }\end{array}$ & $\begin{array}{l}\text { Mahasiswa mewujudkan } \\
\text { desain yang telah } \\
\text { dirancang dalam bentuk } \\
\text { karya nyata yaitu } \\
\text { rangkaian bunga, } \\
\text { rangkaian bunga } \\
\text { dikombinasikan dengan } \\
\text { janur. }\end{array}$ & $\begin{array}{l}\text { Memproses } \\
\text { aktivitas dalam } \\
\text { pembuatan } \\
\text { produk nyata }\end{array}$ \\
\hline
\end{tabular}


5. Memfasilitasi mahasiswa melakukan evaluasi dan refleksi terhadap desain dengan karya nyata sekaligus mengamati kreativitas dan kualitas rangkaian sesuai tema.

$\begin{array}{ll}\text { HASIL: } & \text { Menyajikan dihadapan } \\ \text { Penyajian } & \text { kelas produk karya nyata } \\ \text { produk karya } & \text { rangkaian bunga, } \\ \text { nyata. } & \begin{array}{l}\text { rangkaian bunga } \\ \text { dikombinasikan dengan }\end{array} \\ \text { Analisis proses } & \text { janur untuk masing-masing } \\ \text { dan hasil proyek. } & \text { kelompok. }\end{array}$

Pengamatan terhadap kreativitas mahasiswa meliputi persiapan, proses, hasil. Persiapan meliputi desain/rancangan, bahan, dan alat. Proses meliputi disiplin dan kerjasama. Hasil meliputi inovasi, kesesuaian, keindahan. Instrument untuk data kreativitas diperoleh melalui lembar observasi kemudian dianalisis secara deskriptif, mengacu pada table 2.

Tabel 2. Konversi Kreativitas dan Respon Mahasiswa.

\begin{tabular}{cc}
\hline Skor & Kategori \\
\hline $85-100$ & Sangat baik \\
$70-84$ & Baik \\
$55-69$ & Cukup
\end{tabular}

\section{HASIL DAN PEMBAHASAN}

Penelitian ini dilakukan pada mahasiswa semester III jurusan PKK-Tata Boga yang memprogram mata kuliah Tata Graha. Penelitian dilakukan dalam 4 pertemuan melalui langkah-langkah pembelajaran berikut:

Pertemuan pertama adalah penyampaian tujuan dan lingkup materi pembelajaran. Diskusi dan tanya jawab klasikal dilakukan untuk penanaman konsep rangkaian bunga dan janur. Pemantapan isi pembelajaran untuk keterampilan dasar rangkaian janur adalah melalui demonstrasi membuat racikan rangkaian janur. Setting kelompok dilakukan berdasarkan jenis kelamin dan kemampuan dasar aktivitas. Penugasan melalui bentuk-bentuk rangkaian yang selanjutnya dilakukan perancangan desain rangkaian bunga, rangkaian bunga dipadukan janur. Diperoleh $12 \mathrm{draftt}$ rancangan rangkaian bunga, rangkaian bunga dipadukan dengan janur.

Pertemuan kedua, melakukan presentasi tentang desain rangkaian oleh masing-masing kelompok. Pembuatan desain rangkaian dilakukan secara kolaboratif melalui ide-ide mahasiswa yang dituangkan ke dalam sebuah Rancangan Persiapan Praktek (RPP), didiskusikan dengan pengajar sebelum dipresentasikan. Tanya jawab, diskusi kelompok dan klasikal dilakukan guna 
pemantapan persiapan praktek. Diperolej 12 desain rangkaian bunga, 12 desain rangkaian bunga yang dipadukan dengan janur.

Pertemuan ketiga, dilakukan persiapan bahan dan alat yang digunakan untuk praktek pembuatan rangkaian bunga. Proses perwujudan rangkaian bunga sesuai desain yang disepakati pada pertemuan kedua. Evaluasi terhadap hasil karya mengacu pada kriteria rangkaian bunga. Diperoleh 12 rangkaian bunga sesuai bentuk dan tema.
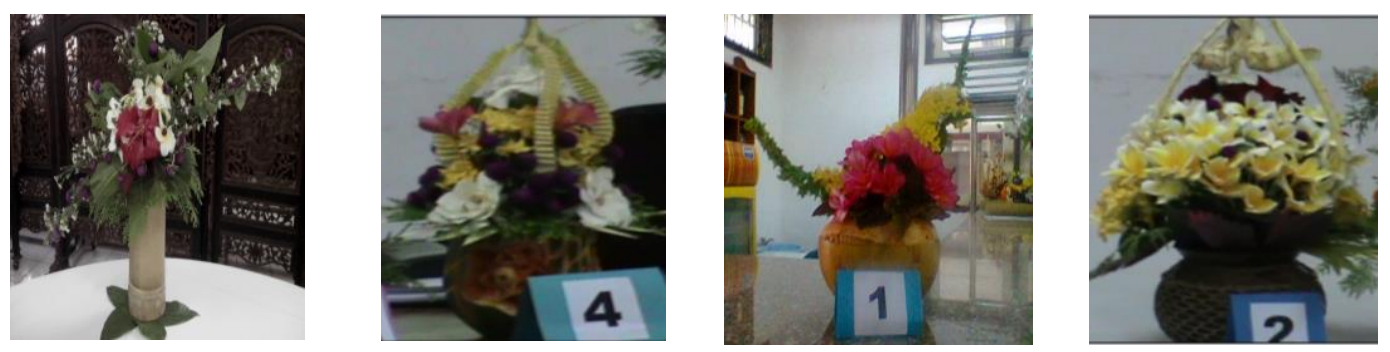

Gambar 1. Rangkaian bunga lokal dan rangkaian bunga dipadukan dengan janur

Pertemuan keempat, dilakukan persiapan bahan dan alat yang digunakan untuk praktek pembuatan rangkaian bunga yang dipadukan janur. Proses perwujudan rangkaian bunga dipadukan janur sesuai desain yang disepakati pada pertemuan kedua. Evaluasi terhadap hasil karya mengacu pada kriteria rangkaian bunga dipadukan janur. Diperoleh 12 rangkaian bunga yang dipadukan dengan janur sesuai bentuk dan tema.

Analisis terhadap kreativitas mahasiswa dalam menuangkan ide-ide melalui rancangan rangkaian bunga, proses pembuatan rangkaian bunga, evaluasi hasil diperoleh rata-rata sebesar 84,8 . Setelah dilakukan pembelajaran berikutnya analisis kreativitas mahasiswa dalam menuangkan ide-ide melalui rancangan rangkaian bunga dipadukan dengan janur, proses pembuatan rangkaian bunga dipadukan dengan janur, evaluasi hasil diperoleh rata-rata sebesar 88,3 yang terkategori sangat baik. Analisis terhadap respon mahasiswa yang dikumpulkan melalui angket diperoleh rata-rata sebesar 91 yang terkategori sangat baik. Contoh hasil rangkaian bunga lokal dan rangkaian bunga dipadukan dengan janur dapat dilihat pada gambar 1 .

Pembelajaran proyek tata graha berbasis budaya lokal merupakan strategi pembelajaran yang terdiri dari empat tahap yaitu isi pembelajaran, kondisi, aktivitas, dan hasil pembelajaran. Tahapan ini sebagai suatu proses pembelajaran 
yang dirasa baru oleh mahasiswa sehingga pada awal pembelajaran mereka sangat antusias untuk mengetahui dan mengalami pengemasan strategi ini. Pembelajaran tata graha yang didasari oleh pemahaman seni baik melalui pembelajaran maupun bakat yang dimiliki mahasiswa memberikan tantangan bagi pengajar sehingga dalam pengelolaan pembelajarannya didukung oleh berbagai perangkat, media, metode pembelajaran.

Penggunaan perangkat modul sebagai pendukung pembelajaran tata graha disiapkan dan digunakan dalam diskusi pertemuan pertama. Media slide digunakan untuk efektivitas penyampaian isi dan tujuan pembelajaran, gambar berbagai bentuk struktur rangkaian, media jadi janur yang langsung didemonstrasikan untuk membuat racikan. Racikan janur ini kemudian dikreasikan nantinya dalam desain rangkaian bunga sehingga muncul keterpaduan rangkaian sesuai tema. Demonstrasi sangat bagus karena sebagian besar mahasiswa belum pernah memegang janur yang nantinya dapat dirangkai tersendiri juga dapat dipadukan dengan bunga. Mahasiswa dapat mengikuti dengan baik, bahkan mereka merasa kekurangan waktu untuk mencoba. Artinya mereka sudah muncul motivasi belajar yang tinggi sebagai awal mereka berkreasi. Adanya upaya dan keterlibatan langsung untuk mencoba membuat racikan, menanyakan kesulitan dalam membentuk racikan menunjukkan strategi pembelajaran ini dapat membuat mahasiswa untuk selalu aktif dan kreatif.

Presentasi tentang desain yang dikembangkan oleh mahasiswa kolaborasi dengan dosen dilakukan dengan baik. Mahasiswa memanfaatkan media slide gambar desain sehingga terjadi komunikasi melalui media dari perancang dengan mahasiswa yang lainnya. Diskusi dan tanya jawab sangat baik karena beberapa hal yang dimunculkan dalam desain masih terkesan monoton. Akhirnya masingmasing kelompok telah menemukan desain yang dianggap betul-betul inovatif melalui pemakaian bunga lokal yang dirangkai sesuai tema dan pemakaian bunga lokal yang dipadukan dengan janur.

Proses pembuatan rangkaian bunga diawali dengan persiapan bahan dan alat praktikum. Pada pertemuan ketiga ini, dilakukan penyampaian tujuan pembelajaran yaitu perwujudan desain dalam bentuk karya nyata rangkaian. Oleh sebab itu dosen memberikan kriteria rangkaian bunga dengan pedoman yang 
harus digunakan dalam proses pembelajaran tersebut. Bentuk rangkaian bunga yang dibuat sebanyak 12 jenis yaitu bentuk L, Bulan sabit, Masal bulat, Masal kerucut, Segitiga, Bentuk S, Diagonal ke kanan, Diagonal ke kiri, gaya jepang, Fantasi, Vertikal, Horisontal. Penyelesaian rangkaian dengan berbagai bentuk ini dominan menggunakan bunga jepun, jempiring, ratna, dan medori. Kreativitas yang muncul adalah dalam memadukan bentuk kelopak bunga, warna, tekstur. Pembentukan kreasi daun sirih yang dipadukan dengan bunga ratna seolah-olah bunga kuncup, pembentukan daun andong, daun paku sebagi pemanis rangkaian. Ratna dan medori yang memiliki kelemahan pada bagian batang namun kelopak bunga mempunyai tekstur kuat memberikan tantangan dan solusi mahasiswa berkreasi dengan pembuatan batang baru atau pengaggantian batang sebenarnya dengan batang yang lebih kuat. Hal tersebut berkreasi dalam upaya untuk memunculkan kreasi dan estetika. Sebagian mahasiswa dalam proses ini masih sangat memerlukan tuntunan karena mereka baru pertama kali mendapat pengalaman mendesain rangkaian kemudian mewujudkan rangkaian jadi. Kesulitan yang dialami adalah pembentukan struktur awal sebelum meletakkan point rangkaian karena kurang pemahaman tentang sifat dan karakteristik bunga. Hasil rangkaian terkagori baik walaupun masih ada rangkaian yang masih memerlukan penyempurnaan cukup tinggi seperti rangkaian tema fantasi, segitiga.

Pada pertemuan keempat yaitu pembuatan rangkaian bunga yang dipadukan dengan janur. Pembelajaran diawali dengan penyampaian tujuan pembelajaran melalui media slide. Gambar hasil praktek rangkaian bunga yang telah dievaluasi oleh masing-masing kelompok. Pemberian contoh rangkaian bunga yang dipadukan dengan janur kemudian disesuaikan dengan desain yang telah dibuat oleh mahasiswa. Persiapan dan penataan bahan maupun alat dilakukan untuk efektivitas praktek. Tema rangkaian masih sama dengan pertemuan ketiga, hanya didalam pertemuan keempat ini dilakukan dengan pemakaian racikan janur. Hal ini memberikan tantangan bagi mahasiswa untuk membuat racikan yang dapat menyatu dengan rangkaian bunga. Racikan janur yang ditata dalam rangkaian janur memunculkan kreativitas yang betul-betul inovatif. Hasil diperoleh sangat bagus karena dari 12 rangkaian terdapat 2 rangkaian yang dikategorikan belum 
sempurna. Kesalahan yang dilakukan adalah pemakaian bahan yang kurang sesuai dengan kontruksi rangkaian.

\section{KESIMPULAN}

Berdasarkan kajian penelitian terhadap pembelajaran graha dapat disimpulkan penerapan pembelajaran proyek berbasis budaya lokal dapat meningkatkan kreativitas mahasiswa jurusan PKK-Tata Boga FTK Undiksha. Peningkatan yang terjadi sebesar 4,6 yaitu dari rata-rata 83,7 menjadi 84,8 dan selanjutnya mengalami peningkatan menjadi rata-rata 88,3. Artinya peningkatan tersebut dari kategori baik menjadi sangat baik. Respon mahasiswa terhadap penerapan model pembelajaran proyek berbasis budaya lokal diperoleh rata-rata skor 91 yang terkategori sangat baik.

\section{DAFTAR PUSTAKA}

Gaer, S. 1998. What is Project Based Learning?, http:// members. aol.com/ CulebraMom/ pblprt.html

Kus Bram. 1999. Teknik dan Seni Merangkai Janur. Bandung : Pionir Jaya.

Lucas dan Sulton S. Cara Praktis Seni Merangkai Janur. Surabaya: CV. Karya Utama.

Lussy Wahyudi . 2008. Panduan merangkai Bunga. Jakarta: PT Gramedia Pustaka.

Santyasa, Sukadi. 2007. Model-model Pembelajaran Inovatif. Pelatihan Profesi Guru di Propinsi Bali. Undiksha.

S. Zaidar Abdurrivai. 1974. Setangkai Bunga Dalam Rumah. Jakarta: Pradnya Paramita.

Suarni, Ketut. 1996. Perkembangan dan Belajar Anak. Singaraja. STKIP.

Suryana. 2000. Kewirausahaan. Jakarta: Salermba Empat.

Suryana. 2003. Kewirausahaan (Pedoman Praktis, Kiat dan Proses Menuju Sukses). Jakarta: Salemba Empat.

Zimmerer, W. Thomas, Norman M. Scarborough. 1996. Entrepreneurship and The New Venture Formation. New Jersey: Prentice Hall International Inc.

http://viewcomputer. Wordpress. Com/ kewirausahaan. Diakses Selasa, 28 Oktober 2013.

http://wartawarga.gunadarma.ac.id/2010/06/makalah-kewirausahaan. Diakses Selasa, 28 Oktober 2013. 